\title{
A METÁFORA DA TRANSITIVIDADE NO GÊNERO NOTÍCIA JORNALÍSTICA: UMA ABORDAGEM SISTÊMICO-FUNCIONAL
}

Gesieny Laurett Neves Damasceno*

Violeta Virginia Rodrigues**

Monica Maria Rio Nobre***

\section{Resumo}

Neste artigo, buscou-se verificar o modo como o Sistema de Transitividade é representado nas notícias jornalísticas a fim de que seus propósitos comunicativos sejam mais eficazmente alcançados. Foi possível identificar, nesse contexto particular de interação, uma representação metafórica do significado, a partir da codificação das categorias semânticas. A esse processo metafórico, atribuímos o rótulo de Metáfora da Transitividade, tendo em vista o conceito mais ampliado de Metáfora sugerido pela Teoria sistêmico-funcional. Limitou-se o foco da investigação ao Sistema de Transitividade codificado em torno do Processo Material abrir, em cláusulas cuja função é a de manchetes das notícias jornalísticas.

Palavras-chave: Teoria sistêmico-funcional, metáfora da transitividade, gênero discursivo.

\section{INTRODUÇÃo}

No uso efetivo da linguagem, o falante possui à sua disposição uma gama de configurações possíveis para expressar um mesmo significado. O que irá determinar uma escolha, em detrimento de outras que poderiam ter sido feitas, será o conjunto de pré-requisitos

* Doutoranda em Letras Vernáculas/Língua Portuguesa pela Universidade Federal do Rio de Janeiro, Rio de Janeiro, Rio de Janeiro, Brasil.

E-mail: gesieny@yahoo.com.br

** Professora Doutora do Departamento de Letras Vernáculas, Setor de Língua Portuguesa da Universidade Federal do Rio de Janeiro, Rio de Janeiro, Rio de Janeiro, Brasil.

E-mail: violetarodrigues@uol.com.br

*** Professora Doutora do Departamento de Letras Vernáculas, Setor de Língua Portuguesa da Universidade Federal do Rio de Janeiro, Rio de Janeiro, Rio de Janeiro, Brasil.

E-mail: profa.monica.nobre@gmail.com 
determinados pelo propósito comunicativo. Neste trabalho, objetivouse investigar o modo como os significados são construídos no gênero notícia jornalística, a partir das categorias semânticas que compõem o Sistema de Transitividade, ou seja, a partir da codificação dos Processos, dos Participantes e das Circunstâncias.

As discussões apresentadas aqui se encontram ancoradas nos pressupostos teóricos da abordagem funcionalista da linguagem, mais especificamente, nos princípios da teoria sistêmico-funcional, cuja finalidade é interpretar como os significados são construídos por intermédio das formas linguísticas (HALLIDAY, 1994). Além dos preceitos da corrente funcionalista, este trabalho constrói sua argumentação em torno da teoria dos gêneros discursivos, que privilegia o estudo da língua em uso.

Uma observação mais criteriosa sobre as formas linguísticas que estruturam o gênero notícia jornalística demonstrou que, de forma bastante recorrente, os jornalistas, a fim de darem relevância aos fatos considerados mais importantes e, consequentemente, atraírem a atenção do leitor, moldam a configuração do Sistema de Transitividade, estabelecendo mudanças de domínio das categorias que compõem esse Sistema Léxico-gramatical. A esse fenômeno de mudança de categoria, estamos atribuindo o rótulo de Metáfora da Transitividade, considerada, em termos hallidayanos, uma variação da expressão do significado.

Este estudo limitou o âmbito de sua investigação às notícias jornalísticas veiculadas no meio on-line. O critério que justifica a escolha desse gênero do discurso se baseia no uso frequente, nesse ambiente particular de interação, das formas linguísticas metafóricas que ocupam o foco das descrições feitas aqui. Para este momento, foram selecionados quatro textos que representam com bastante propriedade as escolhas linguísticas feitas pelos jornalistas com o intuito de despertar a atenção do leitor para os fatos relatados. O fenômeno retratado aqui, ou seja, a expressão metafórica do significado, foi investigado nas cláusulas que compõem as manchetes das notícias jornalísticas, visto ter sido esse o ambiente em que as configurações metafóricas se revelaram mais produtivas, por motivos discursivamente bem delimitados, conforme veremos nas discussões que se seguem. 
2 A Linguística SISTÊMICO-FUnCIONAL E A NOÇÃo DE GÊNEROS DISCURSIVOS

Este artigo propõe-se a investigar, à luz dos pressupostos teóricos do funcionalismo sistêmico-funcional, a importância do Sistema de Transitividade no processo de construção de significados nas situações reais de uso da língua. Apesar de não ser um campo de estudos unificado, pois congrega diferentes versões de análise do sistema linguístico, o funcionalismo, de modo geral, fundamenta-se nas proposições de que a língua deve ser analisada com base nas situações reais de uso e o estudo das formas linguísticas não deve ser feito desvinculado do estudo de suas funções, visto que a estrutura reflete e é motivada pela função. Nesta pesquisa, as análises propostas vinculam-se aos preceitos da vertente funcionalista denominada de linguística sistêmico-funcional, cujo principal expoente é o britânico Michael A. K. Halliday.

No quadro teórico da linguística sistêmico-funcional, a linguagem deixa de ser um mero conjunto de regras e uma representação do pensamento e passa a ser vista como o lugar de interação e, especialmente, como um recurso para a construção de significados (HallidaY, 1994, p. xxvi). A abordagem sistêmico-funcional é uma teoria do significado enquanto escolha. Para essa vertente teórica, a língua se organiza em torno de duas possibilidades alternativas: a cadeia (sintagma) e a escolha (paradigma). Levar em conta o nível sistêmico implica dizer que a gramática é vista como um sistema de escolhas possíveis não arbitrariamente motivadas, ainda que nem sempre consciente, uma vez que o grau de consciência pode variar de uma escolha subconsciente até uma escolha mais consciente.

Por ter como objetivo principal estudar a língua nas situações reais de interação, a abordagem hallidayana sempre analisa o texto, que é visto como parte da língua realmente falada ou escrita, para efeitos de comunicação, por pessoas reais em situações reais (BLoor e Bloor, 2004, p. 04). De acordo com Halliday e Matthiessen (2004, p. 3), o significado de um texto só pode ser explicado a partir da relação do sistema linguístico como um todo, ou seja, para se alcançar a interpretação do texto, é preciso que haja a interpretação do contexto, da situação, da cultura e da sistemática relação entre texto e contexto. De acordo com a teoria sistêmico-funcional, um texto ocorre em dois 
contextos, um dentro do outro: o contexto de cultura e o contexto de situação.

Conforme esclarece Butt (2000, p. 3), o contexto de cultura é a soma de todos os significados possíveis de fazerem sentido em uma cultura particular. Dentro do contexto de cultura, falantes e ouvintes usam a linguagem em contextos específicos, imediatos, conhecidos na linguística sistêmico-funcional como contexto de situação. $\mathrm{Na}$ teoria sistêmica, o contexto de situação exerce papel fundamental, pois é por intermédio dele que os participantes obtêm grande parte das informações sobre os significados que estão sendo negociados no instante da interação. Quando a linguagem é analisada na interação real, observa-se a existência de variáveis contextuais, conhecidas pela linguística sistêmico-funcional como campo - o que está acontecendo; relação - natureza da ligação entre os participantes; e modo - o meio e o papel da linguagem (pode ser de modo linguístico ou não linguístico). Esses fatores concernentes ao contexto de situação afetam sobremaneira a escolha, a estruturação e a natureza do texto, pois refletem as três funções que, segundo Halliday (1994, p. xiii), constituem os propósitos principais da linguagem. São as chamadas metafunções da linguagem, a saber:

Metafunção ideacional: a linguagem é usada para organizar, compreender e expressar as nossas percepções do mundo e de nossa própria consciência;

Metafunção interpessoal: a linguagem é usada para nos permitir participar de atos comunicativos com outras pessoas, para assumir papéis e para expressar e entender os sentimentos, as atitudes e os julgamentos;

Metafunção textual: a linguagem é utilizada para relacionar o que é dito (ou escrito) para o mundo real (BLOOR e BLOOR, 2004, p. 08).

$\mathrm{Na}$ teoria sistêmico-funcional, as diferentes redes sistêmicas codificam diferentes espécies de significado, ligando-se, pois, às diferentes funções da linguagem (Neves, 2001, p. 60). O Sistema de Transitividade (foco deste estudo), por codificar a experiência do mundo, 
liga-se à função ideacional. Dessa forma, para muito além da familiar dicotomia entre verbos transitivos e intransitivos, a Transitividade é compreendida por essa corrente teórica como o sistema que permite identificar as ações e atividades humanas que estão sendo expressas no discurso e que realidade está sendo retratada (FurTado da CunHA e SouZA, 2007, p. 53).

Visto que uma análise sistêmico-funcional parte da premissa de que cada escolha linguística constrói uma representação diferente de uma determinada experiência e que a forma é importante para responder às questões relativas a tais diferenças, como o efeito comunicativo conseguido por intermédio de uma escolha e não de outra, a hipótese subjacente, neste artigo, é a de que as várias representações do Sistema de Transitividade se encontram estritamente relacionadas aos propósitos comunicativos dos gêneros discursivos - em especial, das notícias jornalísticas, nosso foco de investigação.

A decisão por eleger o estudo da Transitividade, no gênero notícia jornalística, justifica-se pelo fato de termos como objetivo observar a língua em uso e, como parte integrante da estrutura comunicativa da sociedade, os gêneros discursivos tornam-se importantes porque o seu estudo engloba uma análise da língua nos seus aspectos discursivos e enunciativos, e não somente em suas peculiaridades formais. Como bem esclarece Marcuschi (2003), o trabalho com gêneros segue uma concepção de língua como atividade social, cognitiva e histórica, e privilegia sua natureza funcional e interativa. Além disso, o fato de os gêneros serem tipos relativamente estáveis de enunciados, ou seja, o fato de possuírem uma forma relativamente padronizada de composição (BAKHTIN, 2000) permite um melhor entendimento acerca da intencionalidade e da natureza estrutural de uma gama maior de textos. ${ }^{1}$

Concernente ao gênero notícia, este se caracteriza, sobretudo, (i) pela função de informar da maneira mais objetiva possível; (ii) pela linguagem "imparcial"; e (iii) pela relação mais ou menos distanciada entre os participantes (Hintze, 2009). No que diz respeito ao processo de produção da notícia, Lage (2003, p. 21) destaca três fases principais:

1. A seleção dos eventos: o autor explica que, em alguns casos, por exemplo, o evento mais importante não é a sequência dos 
fatos, como abrir os olhos, consultar o relógio, escovar os dentes, mas o tempo decorrido entre essas ações. Cabe, portanto, ao jornalista omitir ou não essas informações de acordo com o enfoque dado no texto;

2. A ordenação dos eventos: o contato, a atenção do interlocutor, fixa-se a partir do evento mais importante ou interessante. Os outros aparecerão em ordem determinada pela motivação do principal;

3. A nomeação: há compromissos e sutilezas nos nomes que se atribuem às coisas.

Cumpre a este trabalho, conforme foi mencionado, descrever de que forma a representação das categorias do Sistema de Transitividade se relaciona com as especificidades do gênero notícia.

\section{O Sistema de TransitividAdE NA TEORIA SISTÊMICO-FUNCIONAL}

De modo geral, na maioria das gramáticas normativas da língua portuguesa, a definição de Transitividade orienta-se pela noção de completude e incompletude verbal: intransitivos são os verbos que possuem predicação completa, ou seja, podem constituir sozinhos o predicado, pois não necessitam de outro termo para completálos; e transitivos são os verbos que possuem predicação incompleta, necessitam, portanto, de um complemento (objeto) para integralizar seu sentido (Said Ali, 1964; Cegalla, 1978; Cunha e Cintra, 1985; Kury, 2004).

Diferentemente do tratamento que é dado à Transitividade nos estudos tradicionais, na perspectiva sistêmico-funcional, o termo é usado em sentido mais amplo, pois se refere a um sistema que descreve a cláusula como um todo, não apenas o verbo e seu objeto. Conforme explica Halliday (1994), o Complexo Transitivo é a categoria gramatical responsável pela representação das ideias, da experiência humana. Por meiodoSistemadeTransitividade, é possível identificar as ações e atitudes humanas que estão sendo retratadas no discurso. Essa identificação se dá por meio dos destes principais papéis de Transitividade: (i) 
Processos: são os elementos responsáveis por codificar ações, eventos, estabelecer relações, exprimir ideias e sentimentos, construir o dizer e o existir, realizam-se tipicamente por meio de sintagmas verbais; (ii) Participantes: são os elementos envolvidos com os Processos, de forma obrigatória ou não, realizam-se por meio de sintagmas nominais; e (iii) Circunstâncias: são as informações adicionais atribuídas aos diferentes processos, são tipicamente realizadas por advérbios ou sintagmas adverbiais.

Os conceitos de Processo, Participante e Circunstância são categorias semânticas que explicam, de maneira geral, como os fenômenos do mundo real são representados nas estruturas linguísticas. A teoria sistêmico-funcional identifica seis tipos de Processos: Material: são os processos do fazer, expressam a noção de que alguma entidade "faz" algo e pode ser feito "para" alguma outra entidade; Mental: são os processos que expressam a apreciação humana do mundo, como crenças, desejos e valores; Relacional: são aqueles que estabelecem uma conexão entre entidades, identificando-as ou classificandoas (podem ser de dois tipos: Atributivos ou Identificadores); Verbal: são os processos que expressam o dizer; Comportamental: são os responsáveis pela construção do comportamento humano; Existencial: são os que representam algo que existe ou acontece. Na construção dos significados, por meio do Sistema de Transitividade, três tipos de Processos são considerados como principais - os Materiais, os Mentais e os Relacionais -; e três como intersticiais - os Comportamentais, os Mentais e os Relacionais.

A cada um desses seis Processos associam-se Participantes específicos, determinados pela semântica do tipo de Processo e Circunstâncias variadas para expressar informações adicionais, mas relevantes ao ato comunicativo, construindo, assim, um domínio particular da experiência. Aos Processos Materiais, por exemplo, associam-se os Participantes Ator - aquele que provoca a ação; e Meta - para quem o processo é direcionado. Aos Mentais, estão associados os Participantes Experienciador - aquele que sente, pensa, deseja ou percebe; e Fenômeno - o fato que é percebido, sentido ou compreendido. Os Participantes, para os Relacionais, são Atributo qualidade dada a outra entidade; e Portador - entidade que "carrega" o 
atributo (Processos Relacionais Atributivos), ou ainda, Característica - a entidade definida; e Valor - o elemento definidor (Processos Relacionais Identificadores). Os Participantes dos Processos Verbais são chamados de Dizente - participante inerente que diz, comunica ou aponta algo; Receptor - participante para quem o processo verbal se dirige; e Verbiagem - participante que codifica o que é comunicado. Os Processos Comportamentais têm os Participantes Comportante - participante consciente, "aquele que se comporta"; e Behaviour participante opcional que estende o Processo. Os Processos Existenciais possuem apenas um Participante, o Existente - entidade que existe (pessoas, objetos, instituições, abstrações, ações e eventos).

Um olhar mais sistemático sobre as formas linguísticas que realizam os significados no gênero notícia evidenciou que, não poucas vezes, os elementos principais que compõem o Complexo Transitivo, por intermédio de movimentos de categorias realizados no interior das cláusulas, assumem funções gramaticais distintas do protótipo, gerando significados diversos. Partindo do princípio fundamental da abordagem sistêmico-funcional de que os significados são construídos a partir das escolhas feitas pelo usuário da língua, no momento da interação, e de que essas escolhas não são aleatórias, pois consideram os dados do contexto e os propósitos comunicativos, entendemos que a seleção de determinados tipos de Processo e a natureza dos Participantes que constituem o Complexo Transitivo das construções linguísticas, em detrimento das outras escolhas que poderiam ter sido feitas, encontramse em estreita correlação com os propósitos comunicativos dos gêneros discursivos. Assim, conforme foi dito, a finalidade deste trabalho é descrever uma das formas de codificação do Sistema de Transitividade utilizadas pelos autores das notícias jornalísticas a fim de obterem maior êxito comunicativo nesse contexto particular de interação.

\section{A Metáfora da Transitividade nas notícias JoRnalísticas}

Com o intuito de alcançar os objetivos propostos, as análises apresentadas aqui tiveram como foco as construções elaboradas em torno do Processo Material abrir, em suas diversas acepções. Apesar de, em termos metodológicos, a unidade mínima de análise ser a cláusula (mais especificamente, as manchetes das notícias), consideramos, para 
efeito de descrição linguística, o texto como um todo. As discussões propostas partem das seguintes notícias jornalísticas:

(1) Páscoa abre 500 vagas na Agência do Trabalhador de Curitiba

Mais de 500 vagas de emprego temporário para a Páscoa estão abertas na Agência do Trabalhador de Curitiba, principalmente para os setores da indústria e do comércio. As oportunidades são, na maioria, para linha de produção e promoção de vendas, com salários entre R \$ 812,00 e R \$ 900,00 mais benefícios, como vale-transporte, alimentação, premiações e adicional noturno.

Para o secretário estadual do Trabalho, Luiz Claudio Romanelli, esta é uma oportunidade para quem busca o primeiro emprego, já que grande parte das vagas não exige experiência. "Muitos trabalhadores temporários são efetivados e continuam trabalhando nas empresas", destacou.

Os interessados nas vagas devem procurar a Agência do Trabalhador de Curitiba, na Rua Pedro Ivo 750, das 8 h às 17 h30, exceto finais de semana e feriados. As vagas requerem idade mínima de 18 anos, e os candidatos devem cursar ou ter concluído o ensino médio.

(Disponível em: <http://www.aen.pr.gov.br>. Acesso em: set. 2013)

\section{(2) Brasília ABRIRÁ EXPOSIÇÃo INÉditA SOBRE A CoPA DO Mundo}

Projeto “Brasil - Um país Um mundo” será lançado nesta terça-feira (17) no Centro de Convenções Ulysses Guimarães com a presença de autoridades e personalidades do esporte.

Os grandes craques e lances do futebol mundial serão relembrados e homenageados na exposição "Brasil - Um país Um Mundo", chancelada pelo Grupo Executivo da Copa do Mundo 2014 (GECOPA) como atrativo oficial de divulgação dos destinos que sediarão o Mundial. A iniciativa é inédita e será lançada para a imprensa na Capital Federal, nesta terça-feira (17), no Centro de Convenções Ulysses Guimarães, às $11 \mathrm{~h}$, com a presença de autoridades e personalidades do esporte.

A exposição possui mais de 1000 fotos, obras de artistas brasileiros de renome especialmente criadas para o evento, dezenas de objetos históricos, vídeos, interatividade e ações educativas, desenvolvidas de forma flexível para atender às diversas demandas estratégicas para a melhor promoção do Brasil, dos Estados e cidades-sede.

As peças são divididas pelas temáticas de arte, história, publicidade, 
tecnologia, moda, diversidade e paixão e sagrado. Em um espaço reservado, haverá totens com a promoção das doze cidades-sede da Copa com o objetivo de promover o turista pelo Brasil durante os 32 dias de jogos programados.

Além das peças expostas, o público poderá se divertir com jogos, palestras, área de relacionamento, além de conhecer de perto ídolos como o jogador Cafú, embaixador do projeto.

A exposição será itinerante e passará pelos doze destinos. Em Brasília, o trabalho ficará aberto ao público até o dia 19 de janeiro. Paralelamente, o projeto contará com campanhas em mídias nacionais, projetos educativos, programas de capacitação e estímulo ao intercâmbio cultural, bem como loja específica.

(Disponível em: <http://www.setur.df.gov.br/>. Acesso em: fev. 2014)

\section{(3) Arena Pernambuco abre mais 200 vagas}

Maiores de 18 anos que quiserem trabalhar na Arena Pernambuco durante os jogos da Copa do Mundo têm nova oportunidade. Serão 200 pessoas selecionadas para atuar na área de hospitalidade, que é o serviço de receptivo no estádio. As inscrições vão até o dia 31 de março e a concorrência exige bom entendimento de inglês, ensino médio completo, além de itens de dinamismo profissional, como proatividade, bom relacionamento interpessoal e facilidade em trabalhar em equipe. Serão 3 mil vagas em todo o Brasil. As inscrições acontecem no site do projeto www.querovestiracamisa.com/hospitalidade.

A responsabilidade pelo trabalho, que inclui a seleção e o treinamento dos profissionais que vão atuar durante o período de jogos, é da CSM Brasil, empresa de gestão e marketing esportivo, selecionada para desenvolver várias atividades nos estádios. Os selecionados receberão diárias de trabalho pelos três dias de treinamento e cinco de jogos. Não foi divulgado o valor, apenas que é "atrativo de acordo com referências de mercado".

A diretora da área de hospitalidade da CSM Brasil, Juliana Nascimento, destacou que os profissionais contratados serão responsáveis pela orientação, informação e controle de acesso nos estádios e que o treinamento é bastante didático e dinâmico. "O treinamento é no início de junho, inclusive com um dia na própria Arena, para que a pessoa saiba o terreno onde está trabalhando e fortaleça sua comunicação na hora de orientar os acessos", destacou. 
A seleção inclui entrevista presencial, programada para 7 de abril, e entrevista em inglês. "O nível do inglês pode não ser necessariamente uma condição eliminatória. $\mathrm{Na}$ disposição dos profissionais dentro do estádio, distribuiremos os profissionais de acordo com a necessidade, então uma pessoa com nível menos avançado do idioma pode ficar em áreas com menos turistas estrangeiros, por exemplo," explicou. Os candidatos escolhidos também receberão um certificado de treinamento e participarão de sorteios de brindes realizados em todas as partidas.

(Disponível em: <http://www.diariodepernambuco.com.br>. Acesso em: fev. 2014)

\section{(4) Aeroporto de Manaus abre área do novo estacionamento}

A área liberada do novo estacionamento, localizada no nível de embarque do aeroporto, contará com 685 vagas, tendo três guaritas de entrada e outras três de saída, devidamente sinalizadas para garantir o bom fluxo de usuários no local.

A Infraero disponibilizará na quarta-feira (23) parte do novo estacionamento de veículos do Aeroporto Internacional de Manaus/ Eduardo Gomes (AM). Com isso, o estacionamento provisório, em funcionamento desde 2011, em virtude do início das obras de reforma e ampliação do terminal manauara, será desativado.

O restante do espaço será liberado após a conclusão das obras do estacionamento no nível de desembarque.

Com a entrega das melhorias, o estacionamento contará com um total de 2.670 vagas, distribuídas ao longo dos dois níveis operacionais que o aeroporto terá. A área do novo estacionamento será de 192,4 mil m². "Esta entrega demonstra o avanço das obras de ampliação e reforma do Eduardo Gomes, reforçando o compromisso da Infraero com a melhoria da infraestrutura dos aeroportos", pontuou o superintendente de Manaus, Aldecir Lima.

(Disponível em: <http://acritica.uol.com.br>. Acesso em: mar. 2014)

Nas manchetes dessas notícias, o processo abrir é empregado em suas diferentes acepções, porém, em todas as representações, ele expressa a noção de que alguma entidade "faz algo a alguma outra entidade", enquadrando-se, portanto, no tipo de Processo Material. Conforme foi dito em parágrafos anteriores, de acordo com a perspectiva da gramática sistêmico-funcional, as cláusulas codificadas com Processos Materiais, além do processo propriamente dito, apresentam, ainda, 
(i) um Participante inerente - denominado de Ator; (ii) Participantes opcionais - denominados de Meta, Extensão e Beneficiário; e (iii) Circunstâncias, que também são de caráter opcional (HALLIDAY, 1994). Em todas as manchetes, aos Processos Materiais associam-se os Participantes Ator e Meta, e, em alguns casos, a Categoria Circunstância também está representada, como será demonstrado mais adiante.

Os conceitos de Processo, Ator, Meta e Circunstância são categorias semânticas que explicam de forma bastante geral como os fenômenos do mundo real são representados como estruturas linguísticas (Halliday, 1994; Halliday e Matthiessen, 2004). No entanto, quando passamos a interpretar a gramática da cláusula de forma mais meticulosa, é possível perceber que as representações linguísticas reunidas sob um mesmo rótulo possuem características semânticas e sintáticas bastante distintas. Um exemplo dessa afirmação pode ser visto com os grupos nominais Páscoa, Brasília, Arena Pernambuco e Aeroporto de Manaus, representativos da categoria Ator nas construções que compõem o corpus deste estudo.

A hipótese defendida neste artigo é a de que as construções representadas nas manchetes (1), (2), (3) e (4) são resultado de um movimento de mudança de categoria gerado no interior das cláusulas, provocando uma nova codificação quanto às funções das estruturas linguísticas que representam o sistema léxico-gramatical. Acredita-se, neste estudo, que essa mudança de categoria é fruto de um processo metafórico, denominado aqui de Metáfora da Transitividade.

O termo Metáfora Gramatical, na qual está inserida a Metáfora da Transitividade, é usado pela linguística sistêmico-funcional para designar a variação na expressão de um dado significado. Ao adotar uma nova perspectiva para a metáfora, Halliday (1994) amplia o conceito tradicional estabelecido pela teoria retórica, na qual a metáfora é definida, fundamentalmente, como a variação no significado de uma palavra. Para a abordagem sistêmico-funcional, relevante é o fato de existirem modos diferentes a partir dos quais os significados podem ser expressos. Segundo o autor, existem duas formas de expressar um significado: uma forma congruente e uma metafórica. A representação congruente, ou menos marcada, é aquela considerada como o modo mais comumente dito em uma determinada língua ou "o modo que é dito na ausência de qualquer circunstância especial” (HALLIDAY, 1994, 
p. 343). Como exemplo, esse autor cita as construções em que ocorre a nominalização, como nas cláusulas a seguir, arroladas por ele:

À noite, os convidados comeram sorvete e então nadaram suavemente. (Forma congruente)

À ceia de sorvete dos convidados, seguiu-se um mergulho suave. (Forma metafórica)

Nesses exemplos, é possível perceber, entre outras coisas, que, na forma metafórica da representação, o locutor opta por uma configuração estrutural nominalizada ao fundir, no substantivo ceia, o processo material comer e a circunstância temporal à noite. Apesar de representarem variações na expressão de um estado das coisas não linguísticas e, portanto, serem potencialmente correpresentacionais, as formas congruente e metafórica não devem ser tratadas como sinônimas, visto que as diferentes codificações contribuem de forma diferente para a construção do significado total.

A partir dos preceitos da teoria sistêmica, a Metáfora da Transitividade está sendo considerada, neste artigo, como o processo em que uma nova expressão de significado ocorre em virtude de uma mudança de domínio entre as categorias do Sistema de Transitividade. De forma mais restrita, tendo em vista as construções que compõem o corpus deste estudo, as análises apresentadas se restringem à mudança de domínio entre a categoria Circunstância e a categoria Participante Ator, conforme representado na figura a seguir:

Figura 1 - REPRESENTAÇÃo DA METÁFORA DA TRANSITIVIDADE NO GÊNERO NOTíCIA

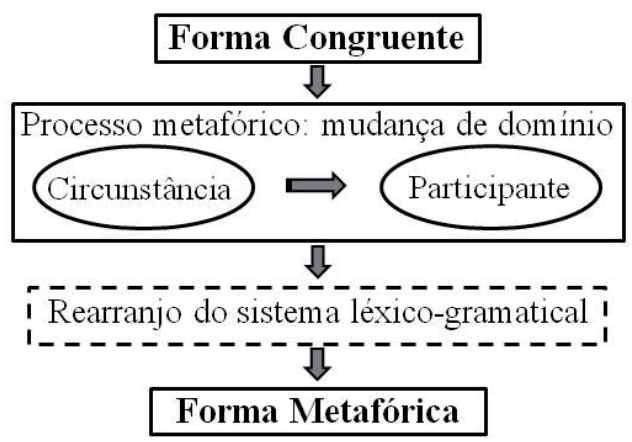


O esquema acima reproduz o movimento de mudança de domínio que ocorre no Sistema de Transitividade expresso em determinadas construções, em que um termo que desempenha a função de Circunstância na forma congruente de representação do significado é codificado como um Participante obrigatório (Ator) na expressão metafórica desse significado. Esse esquema simula, portanto, o processo de configuração das cláusulas (1), (2), (3) e (4), já que a descrição proposta aqui as considera como uma variação na expressão de um significado. As representações que se seguem permitem observar as formas congruentes ${ }^{2}$ dessas expressões linguísticas, bem como evidenciam a mudança de domínio que ocorre entre as categorias Circunstância e Participante (Ator) no Sistema léxico-gramatical:

(1) Páscoa abre 500 vagas na Agência do Trabalhador de Curitiba (forma metafórica)

(1.1) 500 vagas são abertas na Agência do Trabalhador de Curitiba no período da Páscoa (forma congruente)

FigurA 2 - REPRESENTAÇÃO DA FORMA METAFÓRICA DO SISTEMA DE TRANSITIVIDADE

\begin{tabular}{|l|l|l|l|}
\hline Páscoa & abre & 500 vagas & na Agência do Trabalhador de Curitiba \\
\hline Participante Ator & Processo & Participante Meta & Circunstância de localização espacial \\
\hline
\end{tabular}

Figura 3 - RepresentaÇÃo dA Forma CONGRUENTE DO SISTEMA DE TRANSITIVIDADE

\begin{tabular}{|l|l|l|l|}
\hline 500 vagas & são abertas & na agência do Trabalhador de Curitiba & no período da Páscoa \\
\hline $\begin{array}{l}\text { Participante } \\
\text { Meta }\end{array}$ & Processo & Circunstância de localização espacial & $\begin{array}{l}\text { Circunstância de } \\
\text { localização temporal }\end{array}$ \\
\hline
\end{tabular}

(2) Brasília abrirá exposição inédita sobre a Copa do Mundo (forma metafórica) (2.2) Exposição inédita sobre a Copa do Mundo será aberta em Brasília (forma congruente)

Figura 4- RePRESENTAÇÃO DA FORMA METAFÓRICA DO SISTEMA DE TRANSITIVIDADE

\begin{tabular}{|l|l|l|}
\hline Brasília & abrirá & exposição inédita sobre a Copa do Mundo \\
\hline Participante Ator & Processo & Participante Meta \\
\hline
\end{tabular}


FiguRA 5- REPRESENTAÇÃO DA FORMA CONGRUENTE DO SISTEMA DE TRANSITIVIDADE

\begin{tabular}{|l|l|l|}
\hline Exposição inédita sobre a Copa do Mundo & será aberta & em Brasília \\
\hline Participante Meta & Processo & $\begin{array}{l}\text { Circunstância de } \\
\text { localização espacial }\end{array}$ \\
\hline
\end{tabular}

(3) Arena Pernambuco abre mais 200 vagas (forma metafórica)

(3.1) Mais 200 vagas são abertas na Arena Pernambuco (forma congruente)

FiguRA 6- REPRESENTAÇÃO DA FORMA METAFÓRICA DO SISTEMA DE TRANSITIVIDADE

\begin{tabular}{|l|l|l|}
\hline Arena Pernambuco & abre & mais 200 vagas \\
\hline Participante Ator & Processo & Participante Meta \\
\hline
\end{tabular}

FiguRA 7- REPRESENTAÇÃo DA FORMA CONGRUENTE DO SISTEMA DE TRANSITIVIDADE

\begin{tabular}{|l|l|l|}
\hline Mais 200 vagas & são abertas & na Arena Pernambuco \\
\hline Participante Meta & Processo & Circunstância de localização espacial \\
\hline
\end{tabular}

(4) Aeroporto de Manaus abre área do novo estacionamento (forma metafórica) (4.1) Área do novo estacionamento é aberta no aeroporto de Manaus (forma congruente)

FigURA 8- REPRESENTAÇÃO DA FORMA METAFÓRICA DO SISTEMA DE TRANSITIVIDADE

\begin{tabular}{|l|l|l|}
\hline Aeroporto de Manaus & abre & área do novo estacionamento \\
\hline Participante Ator & Processo & Participante Meta \\
\hline
\end{tabular}

Figura 9- REPRESENTAÇÃo DA FORMA CONGRUENTE DO SISTEMA DE TRANSITIVIDADE

\begin{tabular}{|l|l|l|}
\hline Área do novo estacionamento & é aberta & no aeroporto de Manaus \\
\hline Participante Meta & Processo & Circunstância de localização espacial \\
\hline
\end{tabular}

O que se observa nas formas congruentes da expressão do significado é o fato de as formas passivas sem a representação do agente terem se revelado como a codificação mais adequada em todas 
as ocorrências analisadas. Essa constatação traz à tona a estratégia utilizada pelo autor da notícia para preencher os requisitos necessários à apresentação dos fatos, a saber: quem faz o que, a quem, quando e onde. Em relação à Transitividade, o título da notícia deve, sempre que possível, apresentar-se como uma proposição completa, com representação linguística das categorias Ator, Meta, Processo e Circunstância. Na configuração do Sistema de Transitividade, no contexto discursivo em questão, estes dois aspectos se mostram determinantes na codificação da cláusula e, consequentemente, na elaboração metafórica dos significados:

1. Foco da informação: uma manchete de notícia cumpre a função de exprimir, de forma objetiva, parte da macroestrutura hipotética de um item noticioso, sendo, assim, utilizada como sinais adequados para fazer previsões eficazes sobre a informação mais importante do texto (VAN DıJK, 2002). Para que esse objetivo seja eficazmente alcançado, a estrutura linguística deve ser ordenada a partir da expressão textual mais relevante, e, não poucas vezes, a estratégia utilizada para desempenhar essa função no gênero notícia jornalística é a Metáfora da Transitividade. ${ }^{3} \mathrm{Na}$ expressão metafórica do significado, os grupos nominais Páscoa, Brasília, Arena Pernambuco e Aeroporto de Manaus abrigam, em cada uma das manchetes analisadas, o termo predicado (Sujeito Gramatical), o ponto de partida da mensagem (Tema) e o elemento retratado como o fazedor da ação (Ator). Esse tipo de representação gera estruturas mais concisas, tanto em termos estruturais quanto cognitivos. Ao se valer desse recurso, o jornalista capta a atenção do seu leitor e o encaminha para os significados que julga mais relevantes na notícia.

2. Ausência de um agente prototípico: apesar de as cláusulastítulo das notícias terem sido construídas em torno de um Processo Material, ou seja, um processo do fazer, não é conveniente (ou, até mesmo, possível) identificar uma entidade individuada que possa ocupar o papel de instigador da ação verbal nesse contexto discursivo. Em outras palavras, na situação real de comunicação, não é comunicativamente relevante atribuir a um único indivíduo 
os fazeres abrir 500 vagas de emprego na Agência do Trabalhador de Curitiba, abrir exposição inédita sobre a Copa do Mundo, abrir área do novo estacionamento etc., por serem estas ações que, pragmaticamente, envolvem um conjunto complexo de agentes, como autoridades políticas, empresários, comerciantes etc. Diante dessa constatação, observa-se que a representação metafórica da categoria Ator se apresenta como uma solução eficaz para a realização completa da proposição na voz ativa da expressão verbal.

A partir dessas observações, é possível compreender a forma como algumas notícias jornalísticas constroem o Sistema de Transitividade em torno de um Processo Material e quais as consequências dessas escolhas na situação comunicativa. As figuras esquemáticas expostas acima demonstram que as cláusulas (1), (2), (3) e (4) se assemelham pelo fato de realizarem a construção do significado por meio de estruturas metafóricas. Conforme foi dito, a metáfora considerada aqui ocorre no interior do Sistema de Transitividade, entre outros aspectos, no instante em que um termo congruentemente circunstancial exerce a função de participante obrigatório, como aconteceu com os sintagmas adverbiais na Páscoa, em Brasília, na Arena Pernambuco e no aeroporto de Manaus, que assumem, na variação metafórica de expressão do significado, a função de Ator nas várias acepções do Processo Material abrir.

A ideia de que essas construções se constituem em expressões metafóricas do significado é corroborada pela tensão existente entre o estrato da léxico-gramática e o estrato da semântica. Conforme foi mencionado nos pressupostos teóricos deste estudo, a categoria do Participante Ator é realizada, prototipicamente, por meio de sintagmas nominais; já a categoria das Circunstâncias é tipicamente realizada por sintagmas adverbiais. Todavia, nas manchetes analisadas, essa correspondência entre os estratos que formam o sistema linguístico não é direta, visto que a representação da categoria Participante Ator resguarda algumas propriedades da categoria Circunstância. A tensão existente entre os estratos pode ser mais facilmente percebida, por exemplo, por meio dos seguintes testes de sondagem: 
1. Passagem da voz ativa para a voz passiva: na configuração prototípica do Sistema de Transitividade (ou congruente), independente da forma em que se encontra a cláusula, se na voz ativa ou na voz passiva, a representação da categoria semântica Ator permanece inalterada (HALLIDAY, 1994).

A aplicação desse exame, nas manchetes das notícias investigadas neste artigo, revela que as expressões linguísticas que codificam o participante Ator na forma ativa das cláusulas codificam, na forma passiva, a categoria semântica de Circunstância, conforme se vê a seguir:

(1.2) 500 vagas são abertas na Agência do Trabalhador de Curitiba na Páscoa.

(2.2) Exposição inédita sobre a Copa do Mundo será aberta em Brasília.

Além de apontarem para a tensão que existe entre o estrato léxico-gramatical e o semântico, as formas passivas das cláusulas que compõem o foco de interesse deste estudo corroboram a ideia anteriormente mencionada de que o verdadeiro agente da ação verbal - o ser individuado que realmente instiga a ação - não se encontra expresso nas orações. Esse fato nos remete a um dos princípios fundamentais da teoria sistêmico-funcional, que é o de transitividade como representação linguística de uma determinada experiência. Assim sendo, nas cláusulas (1), (2), (3) e (4), a categoria semântica de Ator funciona como uma representação, ou seja, o elemento que o falante retrata como aquele que faz a ação na sua interpretação do processo da experiência humana. Dito de outra forma, na sua representação da experiência, a partir da gama de configurações possíveis, o falante traduz o Complexo Transitivo da forma como este melhor se adéqua à expressão do sentido pretendido e aos efeitos que deseja provocar em seu interlocutor.

2. Perguntas "quem fez o quê?" ou "o que aconteceu a?": nas construções cujo Sistema de Transitividade se aproxima do protótipo da categorização, a resposta a essas perguntas evidencia os participantes dos processos materiais, tanto dos concretos (eventos físicos) quanto dos fazeres abstratos e, ainda, dos 
acontecimentos - todos gramaticalmente tratados na linguagem como tipos de ação. Por exemplo, em O leão pegou o turista, a pergunta quem pegou o turista? revela o Participante Ator do Processo, e a pergunta o que fez o leão? coloca em evidência o Participante Meta (HallidAY, 1994).

Nas cláusulas analisadas, apesar de as expressões linguísticas Páscoa, Brasília e Arena Pernambuco codificarem o Participante Ator, as perguntas mais apropriadas a serem feitas a essas representações são: quando serão abertas 500 vagas na Agência do Trabalhador de Curitiba?; onde será aberta a exposição inédita sobre a Copa do Mundo?; onde serão abertas mais 200 vagas?; e onde será aberta área do novo estacionamento? A resposta a essas perguntas coloca em evidência sintagmas adverbiais de tempo e de lugar, elementos que tipicamente codificam a categoria Circunstância de Localização (temporal e espacial, respectivamente), não a de Ator.

3. Retomada da categoria ao longo do texto: nos casos em que ocorre a variação metafórica, ou seja, em que um termo congruentemente circunstancial é representado como um Participante obrigatório, é muito comum o grupo nominal que exerce a função de Participante Ator ser retomado, ao longo do texto, como um grupo adverbial, codificando, portanto, a função de Circunstância, conforme exemplificado a seguir:

Texto (2) Em Brasília, o trabalho ficará aberto ao público até o dia 19 de janeiro.

Texto (3) Maiores de 18 anos que quiserem trabalhar na Arena Pernambuco durante os jogos da Copa do Mundo têm nova oportunidade.

A tensão que se percebe entre os estratos da léxico-gramática e da semântica é mais um indicativo de que as cláusulas que compõem as manchetes das notícias jornalísticas representam uma variação na expressão do significado, configurando, assim, a forma metafórica de realização do significado, em razão de um contexto discursivo com propósitos bastante delineados. 


\section{Conclusão}

Ao adotar como aporte teórico as proposições do funcionalismo linguístico sistêmico-funcional, as reflexões propostas neste artigo se dirigem para a multifuncionalidade das estruturas linguísticas e se distanciam da preocupação em analisar a organização gramatical das orações dissociadas de seu contexto discursivo de elaboração. Por ser vista como o lugar da interação, a linguagem considerada neste estudo é aquela utilizada nas situações reais de comunicação, pois é no uso efetivo da língua que os significados são construídos e reconstruídos através das escolhas linguísticas realizadas.

Assim, partindo do fundamento de que as escolhas linguísticas feitas pelo usuário da língua não são aleatórias, mas são feitas com base nos propósitos comunicativos a que se pretende chegar, buscouse compreender como a codificação das categorias que operam o Complexo Transitivo - Processo, Participante e Circunstância - se correlacionam com os propósitos comunicativa do gênero notícia jornalística. Para tanto, a Transitividade foi analisada na totalidade da cláusula, não considerando apenas o grupo verbal, como ocorre nos estudos no âmbito das gramáticas tradicionais.

O gênero notícia possui uma função bastante definida no domínio discursivo jornalístico. A notícia se define, no jornalismo moderno, como o relato objetivo de uma série de fatos a partir do fato mais importante (Lage, 2003). Consideradas as especificidades desse gênero, um olhar mais criterioso sobre as representações linguísticas revelou que, muito frequentemente, o autor da notícia lança mão de uma representação metafórica das categorias constantes no Sistema de Transitividade com o objetivo de tornar o processo de informação mais dinâmico e, assim, atrair a atenção do leitor para o texto.

A realização metafórica da Transitividade, no contexto particular desse gênero, ocorre como um recurso que o usuário da língua utiliza para colocar em evidência, de maneira bastante objetiva, os fatos que devem ganhar relevo no ato da informação. Além disso, a representação metafórica do Participante Ator revelou-se como uma estratégia bastante produtiva na composição de uma proposição completa, com as categorias principais da Transitividade representadas (Participantes, Processo e, em alguns casos, Circunstância), ainda que os atores 
prototípicos das ações expressas pelos processos materiais não sejam discursivamente identificados.

A ideia de expressão metafórica do significado é corroborada pela constatação de que se estabelece, nesta representação linguística, uma tensão entre o estrato da léxico-gramática e o da semântica. A relação direta que haveria entre esses dois estratos é desconstruída, uma vez que a expressão linguística que configura a categoria de Participante Ator mantém aspectos da categoria Circunstância, conforme foi demonstrado.

Ao buscar analisar o Sistema de Transitividade por um viés funcional e discursivo, elencando possíveis motivações funcionais para as realizações linguísticas, este estudo endossa uma tendência que, a cada dia, tem se confirmado como uma boa alternativa para os estudos da língua. Seu interesse de investigação vai além da estrutura gramatical, buscando no contexto discursivo as motivações para as formas linguísticas.

THE METAPHOR OF TRANSITIVITY IN GENRE JOURNALISTIC NEWS: AN APPROACH SYSTEMIC-FUNCTIONAL

\section{ABSTRACT}

In this study, we sought to examine how the System of Transitivity is represented so that the enunciation purposes of journalistic news genre are achieved more efficiently. Could be identified in this particular context of interaction, a change in the semantic categories of Circunstance and Participant Actor involving the Processes of the type Material. We call this change the Metaphor of Transitivity, considering the more expanded concept of Metaphor suggested by systemic-functional linguistics. The research was limited to the Transitivity System coded around the Material Process open performed on clauses whose function is to journalistic news headlines.

KEY WORDS: Systemic-functional approach, metaphor of transitivity, discourse genre. 
LA METÁFORA DE LA TRANSITIVIDAD EN EL GÉNERO NOTICIA PERIODÍSTICA: UN ABORDAJE SISTÉMICO-FUNCIONAL

\section{RESUMEN}

En este artículo, se buscó analizar la manera como el Sistema de Transitividad es representado a fin de que los propósitos comunicativos del género noticia periodística sean alcanzados de modo más eficaz. Fue posible identificar, en ese contexto particular de interacción, una representación metafórica del significado, a partir de la codificación de las categorías semánticas. A ese proceso metafórico, atribuimos el rótulo de Metáfora de la Transitividad, teniendo a la vista el concepto más ampliado de Metáfora sugerido por la Linguística Sistémico-funcional. Se limitó el foco de la investigación al Sistema de Transitividad codificado alrededor del Proceso Material abrir en cláusulas cuya función desempeñada es la de sucesos recientes de las noticias periodísticas.

Palabras Clave: Teoría sistêmico-funcional, metáfora de la transitividad, género discursivo.

\section{Notas}

1. A discussão teórica sobre a dicotomia gênero textual e gênero discursivo não se constitui como objetivo deste texto.

2. Como não existem parâmetros teóricos que assegurem a aplicação desse conceito, as representações descritas aqui são apenas algumas das possíveis formas congruentes das expressões linguísticas em foco.

3. Diferentemente do processo de Ergatividade, em que o termo denominado de Médio equivale ao Participante Ator nas cláusulas intransitivas e ao Participante Meta nas cláusulas transitivas, no processo identificado aqui como Metáfora da Transitividade, a função de Ator é codificada por um termo congruentemente circunstancial.

\section{REFERÊNCIAS}

Bakhtin, M. Estética da criação verbal. Tradução de Maria E. G. G. Pereira. São Paulo: Martins Fontes, 2000.

BloOR, T.; BLOOR, M. The functional analysis of English: a hallidayan approach. London: Arnold, 2004. 
ButT, D. Using functional grammar: an explorer's guide. 2. ed. Sydney: Macquarie, 2000.

Cegalla, D. P. Novíssima gramática da língua portuguesa. 18. ed. São Paulo: Nacional, 1978.

Cunha, C.; CinTra, L. F. L. Nova gramática do português contemporâneo. Rio de Janeiro: Nova Fronteira, 1985.

Furtado da Cunha, M. A.; Costa, M. A.; Cezario, M. M. Pressupostos teóricos fundamentais. In: CunHA, M. A. F. et al. (Orgs.). Linguística funcional: teoria e prática. Rio de Janeiro: DP\&A, 2003.

Furtado da Cunha, M. A.; Souza, M. M. Transitividade e seus contextos de uso. Rio de Janeiro: Lucerna, 2007.

Halliday, M. A. K. An introduction to functional grammar. 2. ed. London: Edward Arnold, 1994.

Halliday, M. A. K.; Matthiessen, C. M. I. M. An introduction to functional grammar. 3. ed. London: Arnold, 2004.

HinTZE, A. C. J. Contribuições de pressupostos básicos do funcionalismo para análise de textos do gênero notícia nos meios impresso, televisivo e on line. In: Antonio, J. D.; Navarro, P. (Orgs.). O texto como objeto de ensino, de descrição linguística e de análise textual e discursiva. Maringá: UEM, 2009.

Kury, A. G. Novas lições de análise sintática. 9. ed. São Paulo: Ática, 2004.

Lage, N. Estrutura da notícia. 5. ed. São Paulo: Ática, 2003.

Marcuschi, L. A. Gêneros textuais: definição e funcionalidade. In: Dionísio, A. P.; Machado, A. R.; Bezerra, M. A. (Orgs.). Gêneros textuais \& ensino. 2. ed. Rio de Janeiro: Lucerna, 2003.

Mira Mateus, M. H. et. al. Gramática da língua portuguesa. 7. ed. Lisboa: Caminho, 2006.

Neves, M. H. de M. A gramática funcional. São Paulo: Martins Fontes, 2001.

SAID Ali, M. Gramática secundária e gramática histórica da língua portuguesa. 3. ed. Brasília: Ed. UnB, 1964.

VAN DIJK, T. Cognição, discurso e interação. Apresentação e organização de Ingedore Villaça Koch. 4. ed. São Paulo: Contexto, 2002.

Recebido em 13 de abril de 2014

Aceito em 3 de julho de 2014 